\title{
Visão geral sobre governança corporativa e análises de situações empresariais críticas à luz de seus eixos centrais
}

\section{Overview of corporate governance and analysis of critical business situations in the light of their central axis}

ROBERTO MINADEO*

\section{RESUMO}

$\mathrm{O}$ artigo trata de vários temas ligados à Governança Corporativa (GC). Seções curtas trazem a relação entre GC e Fusões e Aquisições, além da prática da GC em uma organização sem fins lucrativos. A Metodologia utilizada é o estudo de casos múltiplos, e somente foram adotados artigos acadêmicos e livros como fontes. Nesses Estudos de Casos não se observaram alguns ou todos os princípios de GC. Foram pesquisadas situações atuais de setores diversos da economia e de diversos países, o que torna o texto atual e interessante. Tais Estudos de Casos foram objeto de análises - no tocante às inobservâncias dos princípios da GC. Nas Conclusões se fazem comparações entre as diversas situações apresentadas. Estudos futuros podem abordar situações problemáticas de GC mediante outras formas, por exemplo, com o uso de fontes primárias.

Palavras-chave: Governança Corporativa; Estratégias Empresariais.

\section{Abstract}

The article addresses several topics related to Corporate Governance (CG). Short sections bring the relationship between GC and Mergers and Acquisitions, as well as CG practice in a non-profit organization. The methodology used is the study of multiple cases, and only academic articles and books have been adopted

Analista em C\&T do CNPq. Participante do Grupo Administração e Sociedade, da Universidade Ceuma, com pesquisas centradas em Estratégia Empresarial. rminadeo@gmail.com . 
as sources. In these case studies some or all of the CG principles were not observed. Were researched very current situations from different sectors of the economy and from different countries, which makes the text current and interesting. Such case studies have been the subject of analysis - regarding non-compliance with the CG principles. In the Conclusions, comparisons are made between the different situations presented. Future studies may address problematic CG situations in other ways, for example through the use of primary sources.

Keywords: Corporate Governance; Business Strategies.

\section{INTRODUÇÃO}

O artigo apresenta uma visão panorâmica a respeito da Governança Corporativa (GC): princípios, elementos históricos marcantes, e os principais sistemas de GC observados em alguns países de destaque. Breves apartados apontam ideias sobre a relação entre GC e Fusões e Aquisições e a prática da GC em uma organização do terceiro setor. Depois, se mostra a Metodologia utilizada - que trata do método do caso. Cumpre destacar também, em relação aos métodos de elaboração do texto, que apenas se utilizaram artigos acadêmicos e livros como fontes. Em seguida, exibem-se os Estudos de Casos Múltiplos, que representam situações críticas, nas quais não se observaram alguns ou todos os princípios de GC. Destaca-se que se buscaram situações atuais de setores diversos da economia e de vários países, conferindo, assim, riqueza ao artigo. Tais Estudos de Casos foram objeto de análises - em relação à aderência aos princípios da GC. As Conclusões e as Referências encerram o estudo. Nas Conclusões se fazem comparações entre as distintas situações expostas.

\section{REFERENCIAL TEÓRICO}

Para Cerda (2000), o sistema de Governança Corporativa (GC) visa: a) prover uma estrutura eficiente de incentivos para a administração da empresa, tendo em vista a maximização de valor; e b) estabelecer responsabilidades e outras garantias para evitar que os gerentes promovam qualquer tipo de expropriação de valor em detrimento a qualquer um dos interessados. 
Sabbatini (2010) aponta que a GC possui dois apoios principais: a delegação de poder (pois as intenções dos gestores podem diferir dos objetivos empresariais) e a assimetria comunicacional - dado que os acionistas majoritários podem deter mais informações que os minoritários, e se beneficiarem disso. Em relação ao primeiro tema, Weston (1969, p. 20-21) afirma ser difícil que ocorra a maximização do valor dos acionistas, em especial em situações de dispersão do controle acionário, pois os executivos tomam as principais decisões - havendo imediatas punições por seus eventuais fracassos e sendo difícil que seus sucessos recebam os devidos prêmios; daí que passou a imperar uma gestão conservadora nas companhias dos EUA após a Segunda Guerra Mundial, vindo a resposta de muitas empresas remunerarem os executivos com ações e opções de compras de ações. No tocante à assimetria de informação no que diz respeito aos recursos intangíveis da empresa, que são de fundamental importância e contribuem para criação de valor, Carvalhal e Bordeaux-Rêgo (S/d) apontam itens como: treinamento, expertise, sistemas de gestão, carteira de clientes etc.; sua não divulgação nos relatórios financeiros pode levar a uma avaliação errônea do valor do negócio por parte dos investidores.

A GC trata da forma de gestão das organizações, abrangendo os diversos vínculos entre processos, normas e procedimentos entre os distintos stakeholders. Também inclui diretrizes para a resolução dos conflitos que venham a surgir. Segundo a economia, a GC visa superar o "conflito de agência", que aparece quando ocorre a separação entre a propriedade e a gestão. Tal conflito decorre da possibilidade de os interesses dos gestores diferirem das metas dos sócios (LADEIRA, 2009).

O movimento da GC teve início nos EUA no início da década de 1980. Com a integração global da economia, a GC passou a ser uma tendência. É algo novo e em desenvolvimento em diversos países, inclusive no Brasil. A diluição do controle do capital de muitas empresas cria um movimento de cisão entre a propriedade e a gestão. $\mathrm{O}$ aumento de Sociedades Abertas, a abertura do capital de empresas que eram fechadas e o aumento do número de investidores no mercado de capitais são elementos que propiciam essa dispersão do controle do capital em muitas firmas (LADEIRA, 2009). 
Ao longo do século XX, a financeirização tornou-se uma força crescente não apenas na economia, mas da sociedade como um todo. No pós-guerra, a produção e o comércio perdem importância em relação ao setor financeiro em vários países. Quase todos os aspectos da vida social foram influenciados pela financeirização, desde a desigualdade, ao poder estatal, aos movimentos sociais, ao planejamento urbano, e às políticas locais. Um dos sinais disso, em 1982, o Conselho de Administração do Chase Manhattan incluía executivos da Ford, General Foods, Macy's, Exxon, Xerox, AT\&T, Pfizer, Cummins e da Bethlehem Steel - entre outras empresas (DAVIS, 2015).

Uma economia girando em torno da financeirização apresenta elevada instabilidade. Tal foi mostrado pelas crises dos anos 1990: do México, da Ásia, da Rússia e da quebra do fundo hedge dos EUA, o Long Term Capital Management. Um sinal dessa avalanche do mundo financeiro: desde 1985, a unidade norte-americana da Deloitte \& Touche analisou e implementou mais de 14 mil ofertas de títulos, com valores totais de mais de US\$ 5 trilhões (ARNOLD, 2009). Em 2008, três dos cinco maiores bancos de investimento independentes dos EUA (Bear Stearns, Lehman Brothers e Merrill Lynch) não sobreviveram. A maior seguradora (AIG) e as duas maiores empresas financiadoras de hipotecas (Fannie Mae e Freddie Mac) foram estatizadas. A maior firma de poupanças (Washington Mutual), e os dois maiores emitentes hipotecários independentes (Countrywide e New Century), faliram (DAVIS, 2015).

Para o Instituto Brasileiro de Governança Corporativa, a GC visa garantir aos acionistas, o controle da diretoria executiva, e que esta siga as estratégias delineadas. A propriedade e a gestão se relacionam mediante o conselho de administração, a auditoria independente e o conselho fiscal (LADEIRA, 2009).

Há um conjunto de estatutos legais e regulamentos que ajudam a embasar as diversas práticas da GC; são elementos dos quais não se pode abrir mão, estão ligados à escolha dos gestores de uma firma e em especial à publicação de seus resultados. Tais partes são vistas como eixos centrais da GC: a) transparência e acesso às informações relevantes ao negócio (disclosure); b) compromisso com prestação de contas de modo responsável e ético (accountability); c) 
senso de justiça e equidade, em especial, no tratamento aos acionistas minoritários (fairness); d) busca pela conformidade às leis do país, nos diversos regulamentos empresariais (compliance). Para esses elementos estarem presentes nas normas de uma empresa, cabe ao conselho de administração, que representa os acionistas, exercer seu papel na companhia - que é o de fixar estratégias à empresa, eleger os dirigentes e fixar seu desempenho, e escolher a auditoria independente que irá avaliar se as diretrizes traçadas estão sendo seguidas. Em função de escândalos empresariais internacionais de grande porte, as leis contábeis tiveram aprimoramentos, também no Brasil, para tornar mais clara a evidenciação contábil. Dados os fluxos internacionais de capitais, ganha importância a criação de uma linguagem universal para os negócios. As peculiaridades contábeis de cada país podem ser fontes de problemas, passíveis de resolução no âmbito da GC (LEAL; FAMÁ, 2007; LADEIRA, 2009; DEDONATTO; BEUREN, 2010; SABBATINI, 2010).

A disclosure é vital para a eficiência do mercado acionário. $\mathrm{O}$ provimento de informações por parte das companhias de capital aberto ocorre pelos mais diversos tipos. A disclosure também proporciona a redução da assimetria de conhecimentos sobre a companhia, entre os investidores - permitindo a atração de fundos diversos, e trazendo maior liquidez às ações (LANZANA, 2004).

A GC para Benites e Polo (2013) é o sistema de valores e padrões de comportamento, pelo qual as empresas possuem responsabilidade tanto em relação aos seus objetivos do negócio quanto em relação aos interesses dos mais variados stakeholders. Os autores acrescentam que o relatório de sustentabilidade se constitui no mais importante elemento da comunicação do desempenho social, ambiental e econômico das companhias, cenário semelhante ao descrito por Caldas, Tambosi Filho e Vieira (2014).

Weston (1969, p. 85-86) defende a importância de comitês financeiros. São criados conjugando know-how de vários profissionais da organização para atuar em problemas pontuais. Um comitê focado na forma de obtenção de recursos poderia ter um horizonte de planejamento de longo prazo, enquanto que comitês ligados ao orçamento podem prender-se a essa ferramenta visando acompanhá-lo ao longo do ano. Outros comitês poderiam tratar de temas como 
salários, por exemplo.

As empresas não podem apenas atender aos interesses dos acionistas, mas a uma ampla gama de públicos direta ou indiretamente aos negócios por elas realizados. No que diz respeito à transparência, a GC vem a ser como um novo modelo de gestão para companhias que aspiram a deter um nível superior de relação com os investidores e o mercado (LEAL, FAMÁ, 2007).

A aquisição de uma empresa de baixa performance pela concorrência é um mecanismo de GC que é orientado externamente. Além disso, há quatro mecanismos internos: a) concentração acionária; b) conselho de administração; c) compensação aos Diretores; e d) estrutura organizacional multidivisional - que permite controlar a atuação de executivos em suas unidades de negócios, evitando que eventuais maus resultados atinjam toda a empresa. O mecanismo interno é ligado à diferenciação entre gestão e propriedade do negócio (HITT; IRELAND; HOSKISSON, 2001, p. 404-406 e 424-425).

Tinoco, Escuder e Yoshitake (2011) afirmam que, em função da concentração de poder, os membros do conselho de administração são, em sua maioria, indicados pelo acionista controlador. Essa situação reduz a possibilidade de uma postura ativa e independente dos conselhos, que é necessária para o cumprimento de suas atribuições legais de fixação da orientação geral dos negócios e fiscalização da gestão dos executivos em prol de todos os acionistas. Assim, para tentar neutralizar essa postura, a GC é reforçada pela criação do conselho fiscal, após a Securities and Exchange Commission - SEC aceitar o conselho fiscal como agente controlador em substituição ao comitê de auditoria. A Lei das Sociedades Anônimas exige o conselho fiscal, mas não de modo permanente. Sua instauração pode ser exigida por acionistas e o órgão se mantém até a próxima assembleia geral ordinária, quando os mandatos dos conselheiros fiscais se extinguem. Competências do conselho fiscal, segundo a Lei: a) fiscalizar os atos dos gestores e aferir a consecução de seus deveres legais e estatutários; b) opinar quanto aos atos dos gestores; c) opinar acerca do relatório anual da administração e a respeito dos demonstrativos financeiros; d) denunciar ao conselho de administração e aos acionistas eventuais atos irregulares; e e) comparecer à assembleia geral de acionistas e à assembleia geral extraordinária 
e opinar sobre matéria de sua competência.

Os valores éticos podem ser minados após uma série de dilemas - que não foram corretamente confrontados. Por sua vez, escolhas infelizes de executivos podem criar vieses éticos. Passos de um programa de compliance: a) divulgar códigos de conduta e treinar o pessoal para apresentar comportamentos com eles condizentes; b) designar pessoas para comitês de compliance; c) criar canais de comunicação, o que pode incluir linhas anônimas; d) apresentar planos internos de monitoramento e auditoria; e) publicar padrões de comportamento; e f) responder de forma célere aos problemas detectados. Mesmo assim, pode haver algo como um cansaço na consecução dos padrões éticos, quando a compliance em relação a esse código deixar de ocorrer (CANNON et al., 2015).

A literatura acadêmica identifica quatro modelos de GC: a) financeiro, focado no retorno dos investidores; b) dos stakeholders, que prioriza a responsabilidade social; c) político, focado em um quadro institucional mais amplo; e d) de procuradoria, que valoriza o poder de os gerentes agregarem valor ao negócio. $\mathrm{O}$ modelo de GC que parece vigorar no Brasil é o financeiro, dada a relevância que assume o conflito de agência entre acionistas controladores e não-controladores e a importância atribuída aos retornos dos investimentos (BERTUCCI; BERNARDES; BRANDÃO, 2006). A adoção das boas práticas de GC definidas pelo Banco Central do Brasil aumenta os custos de operação de cooperativas de crédito. Organismos como: assembleias, conselhos, auditoria e gestão profissionalizada representam esse custo. Uma cooperativa de Minas Gerais, existente desde 1991, com 12 mil associados, 7 agências, 71 funcionários e ativos totais de R\$ 75 milhões ao final de 2011 foi objeto de uma pesquisa. O método escolhido foi o estudo de caso, mediante o envio de questionários, havendo 81 respondentes. Os órgãos da gestão, como Conselho de Administração, Conselho Fiscal e Diretoria Executiva, foram vistos como eficientes. Metade dos cooperados vislumbra que organismos como Conselho de Administração, Conselho Fiscal, Diretoria Executiva, Auditoria e Assembleia Geral Ordinária apresentam custos elevados - vistos pela maioria dos cooperados como investimento, e cujas decisões 
desses organismos são bem recebidas (TRINDADE; NETO, 2014).

Sobre a relação entre custos de auditoria e a qualidade da GC, um estudo a partir de uma amostra de 131 empresas em 2009, trouxe relação negativa entre GC e os custos de auditoria independente. Nas empresas analisadas, o efeito risco parece predominar, ou seja, uma GC superior reduz o risco da auditoria independente permitindo a redução das taxas cobradas. A qualidade da GC foi avaliada mediante variáveis ligadas à participação em segmentos diferenciados de GC da Bovespa, estrutura de propriedade, e a existência de comitê de auditoria e departamento de auditoria interna. Apesar de a literatura internacional, especialmente oriunda de mercados com propriedade dispersa, mostrar relações positivas e negativas, a relação positiva é mais frequente. Os resultados aqui encontrados podem mostrar que, em contextos de maior concentração os efeitos sejam diversos. A pesquisa também avaliou o impacto da contratação de uma das quatro grandes empresas de auditoria: o serviço prestado é mais caro e com maior frequência se contratam serviços adicionais (BORTOLON; NETO; SANTOS, 2013).

Duas situações ilustram como a atuação de auditorias externas pode ter deixado a desejar no setor financeiro durante a crise de 2007-2008 nos EUA e suas consequências. O Lehman Brothers recebeu um parecer da auditoria externa "sem reservas" ao início de 2008, e também teve um laudo de auditoria uma avaliação positiva da auditoria em 10/07/2008, relativa ao trimestre fiscal anterior. Mas, em agosto o banco já estava em situação difícil e solicitou proteção falimentar em 14/09/2008. O Bear Stearns, quinto maior banco de investimentos dos EUA, recebeu um parecer da auditoria externa "sem reservas" em 28/01/2008, mas já em 10 de março desse ano seus problemas vieram a público, e, em 14/03/2008, com apoio do governo, foi vendido ao JP Morgan Chase (SIKKA, 2009). O Lehman Brothers teve outro problema: pagou ao seu presidente cerca de US $\$ 450$ milhões entre 2000 e 2007, logo antes de sua falência - uma falha em equidade. Em 2008, a Merrill Lynch perdeu US\$ 12 bilhões e foi adquirida pelo Bank of America. Além disso, o presidente do Lynch insistiu em solicitar pagamentos de US\$ 10 milhões após a venda ao Bank of America e fez pagamentos secretos de última hora a outros executivos, no valor de US\$ 15 milhões; quando isso 
veio à tona, ele foi obrigado a se demitir da nova entidade, pois o clima em Wall Street já lhe era hostil (WAGNER III; HOLLENBECK, 2014, p. 225-259).

\subsection{A prática da GC em diversos países}

Em geral, há dois extremos em continuum de uma escala de GC: por um lado o padrão britânico ou norte-americano (ancorado no mercado acionário), e, por outro lado, o que se observa na Alemanha e Japão (apoiado em bancos). O Canadá está em uma situação intermediária, pois: a) há um controle acionário concentrado como o alemão, sem restrições à existência de dois tipos de ações; b) $\mathrm{O}$ Conselho de Administração nos EUA ou Grã-Bretanha apresenta profissionais de fora da empresa, na Alemanha há representantes dos acionistas e dos colaboradores; no Canadá há gestores, acionistas e profissionais externos; c) há diferenças quanto à organização das instituições financeiras: nos EUA, costumam ser holdings, com funções mais abrangentes do que apenas as bancárias; na Alemanha, tais instituições se abrigam sob um único guarda-chuva institucional; no Canadá normalmente um banco, detém o controle de várias subsidiárias; e d) no Canadá, o setor bancário é concentrado em poucas instituições de grande porte, enquanto que nos EUA há maior dispersão (PICHHADZE, 2005).

No modelo norte-americano, a posse de ações pela Direção e pelo Conselho de Administração pode influir de duas formas: a) melhora o desempenho empresarial, reduzindo as chances de vir a ser adquirida de modo hostil; e b) se tal posse não tiver relação com a performance e se os gestores auferem rendimentos de seu trabalho, os últimos podem não estar interessados na venda do negócio; a resistência desse grupo teria maior eficácia quanto maior fosse o volume de ações detido por eles (WEISBACH, 1993).

Em 1994, apenas três empresas alemãs representavam um terço do volume das Bolsas de Valores: Deutsche Bank, Daimler-Benz, e Siemens; e as seis maiores companhias do país respondiam por 50\% desse volume. De 1981 a 1988, houve 51 aberturas de capital na Alemanha no principal mercado acionário, contra 284 no principal mercado acionário britânico. A fusão Daimler Benz-Chrysler Corporation foi o maior negócio desse tipo envolvendo duas entidades 
de países distintos (cross-border merger) do setor industrial, e se esperava que pudesse contribuir em trazer à Alemanha parte do estilo norte-americano de GC, mais focado nos acionistas, enquanto que o estilo alemão visa os interesses mais amplos dos stakeholders. Um tema que poderia avançar na GC alemã seria a transparência da remuneração dos executivos. Por sua vez, acionistas com ao menos $5 \%$ das ações em empresas alemãs podem sugerir temas ao Conselho de Administração, inclusive alterações no Estatuto da Empresa, também algo distinto do que ocorre nos EUA (GORDON, 2000).

O estilo alemão de GC leva a que as F\&A's desse país sejam amigáveis. Razões para tal (HÖPNER; JACKSON, 2001): a) estrutura concentrada e estável do controle do capital - que impede F\&A's hostis; b) ação dos funcionários das empresas nos Conselhos de Administração, contrárias às F\&A's, pelos naturais temores de reestruturação e de cortes de empregos resultantes de tais operações; c) menor transparência na contabilidade alemã, o que amplia os riscos, dado que há maiores chances de dívidas não claras, além de outras questões; d) existência de dois níveis de Conselho: Conselho de Administração e Conselho de Direção. Os membros do primeiro apenas podem ser removidos antes do final de seus mandatos com $75 \%$ dos votos dos acionistas. Os Diretores normalmente possuem cinco anos de mandato; e) cultura do país, voltada à engenharia e produção; f) atuação dos Bancos, cujo papel é importante, mesmo em companhias cujo controle se encontra bastante fragmentado. Porém, aos poucos, tal quadro vem se alterando, havendo bancos que apoiam F\&A's hostis, como a compra da Hoesch pela Krupp em 1991.

De fato, segundo Franks e Mayer B. (1998), na siderurgia alemã, havia um histórico fracassado de fusões amigáveis, o que levou a Krupp a buscar uma aquisição no mercado, pois o momento de uma consolidação na siderurgia do país era chegado. A Hoesch era um alvo ideal, pois não era controlada por nenhum grupo industrial. Em outubro de 1991, a Krupp já detinha 24,9\% da Hoesch, o que foi facilitado pelo fato de haver de $15 \%$ a $18 \%$ de suas ações na bolsa de Londres e pela queda das bolsas causada pela Guerra do Golfo. Em junho de 1992, a Hoesch aceitou a proposta de fusão.

Nos EUA, é obrigatória a adoção e divulgação das diretrizes de GC e de um código de conduta e ética, o que não há no Brasil, 
dificultando aos investidores a analisar as empresas de capital aberto (ANDRADE, 2005). Sabbatini (2010) acrescenta que, no Brasil, há grande concentração da propriedade, elevado financiamento oriundo de recursos estatais - o que redunda em baixa proteção aos minoritários. A autora mostra melhorias nesse quadro: a) a Lei das Sociedades por ações de 2001; b) a reforma do Código Civil em 2002; c) maior presença de investidores institucionais e estrangeiros; e d) mecanismos como processos de F\&A's, sucessões e privatizações.

$\mathrm{Na}$ ótica anglo-saxônica, o papel da empresa na sociedade é o de criar riqueza aos acionistas, o que faz parte das normas vigentes. Os gestores têm uma responsabilidade fiduciária para agir no interesse dos acionistas, o que legitima a ótica da GC desses países. Assim, em 2004, um acordo com os investidores da WorldCom custou US\$ 2,7 bilhões ao Citibank e, em 2005, esse banco pagou US\$ 2 bilhões em uma ação coletiva de fraude movida por acionistas da Enron (FORTUNA, 2007).

Pesquisas mostram que os valores dominantes de culturas nacionais possuem efeitos profundos sobre as empresas e o comportamento organizacional - em especial, o grau de formalização e a forma de tomada de decisão. Em firmas francesas e italianas, predominam estruturas fortes e centralizadas. Na Alemanha e Holanda, há mais descentralização. Porém, há empresas de um mesmo país com culturas marcadamente diversas, como ocorre nas norte-americanas IBM, Ford e Du Pont (OLIE, 1990).

Na Alemanha, muitas ações de empresas estão concentradas em bancos, que costumam ter postos nos Conselhos de Administração. Além disso, não há impostos sobre ganhos de capital de longo prazo - o que deixa em segundo plano os lucros trimestrais, que são especialmente valorizados nos EUA. Outra vantagem das empresas alemãs em relação às empresas dos EUA se encontra no tocante à menor rotatividade de pessoal, o que permite maiores investimentos na formação de seus recursos humanos, que também se observa no Japão (PORTER, 1993, p. 427 e 665).

Entre 1962 e 1971, a Coreia do Sul enfatizou o crescimento da infraestrutura e da indústria exportadora. Essa política incluiu a participação dos chaebols, como grupos intensivos em mão de obra, com foco nas exportações, e apoio governamental na concessão de 
empréstimos e com baixos impostos. A Samsung e a LG ingressaram na eletrônica nesse período e a Hyundai na indústria automotiva e na construção. A Ssangyong destacou-se na produção de cimento. Nos anos 1970, a Hyundai ingressou em estaleiros, aço e indústria elétrica pesada; a Samsung em eletrônica e em engenharia pesada; a Daewoo também passou a atuar em engenharia pesada, estaleiros e em química; a LG ingressou em peças eletrônicas e a Sunkyung em petroquímica. Nos anos 1980, o governo reagiu ao segundo choque do petróleo, passando a focar em seis setores, incluindo automóveis e equipamentos de geração elétrica. A partir da crise asiática de 1997-1998, a união de forças entre política e negócios passou a ser vista como antiética: as empresas deveriam buscar lucros em um livre mercado, em um ambiente de competição, ao invés de se protegerem mediante tratamento preferencial. Tal junção de forças pode minar tanto a política quanto a economia, trazendo ineficiências à sociedade. Nos chaebols, as leis ligadas à accountability e à autoridade dos proprietários, diretores e auditores, não costumam contar com amparo da organização - sendo a responsabilidade desses grupos, em caso de falhas, compartilhada por toda a sociedade. Tal tendência é reforçada, pois os mecanismos internos, como Conselhos de Direção, auditores e Reuniões de Acionistas, são controlados pelos proprietários e executivos. Assim, a GC passou a ser mais presente como fator de competitividade empresarial na Coreia; investidores passaram a preferir empresas com estruturas mais transparentes (JUNG, 2013).

No Japão, adota-se um Conselho de Administração com menor alcance do que o alemão, pois não possui poder de trocar nem de sugerir diretores. Além disso, o Conselho de Administração não representa necessariamente nem os interesses dos acionistas nem os dos colaboradores - sendo sua função basicamente a de verificar o grau de compliance dos membros da direção e de conferir os resultados financeiros. Até os auditores costumam ser executivos que foram promovidos, e que recebem informações da direção (CHIZEMA; YOSHIKATSU, 2012).

No final dos anos 1990, algumas varejistas japonesas enfrentaram problemas de solvência. Além de problemas de mercado, podem ser vistas razões que derivam da GC, como diversificações 
malsucedidas. A relação entre os principais bancos e as empresas é um ponto central do sistema japonês de GC, e está ligado à escolha de diretores, à existência de participações acionárias cruzadas entre os membros do grupo comandado pelo banco e ao fornecimento de recursos financeiros. Em fevereiro de 2000, a Nagasakiya pediu proteção legal aos seus credores; com dívidas de 380 bilhões de ienes e receitas de 314 bilhões em 1998, era a 19a . maior varejista, e sua quebra foi a maior do setor até então. A rede apresentava queda de vendas e iniciara, em 1988, uma diversificação para imóveis, aluguel de vídeos, financiamento ao consumidor e lazer. Também as redes varejistas Sogo e Daiei tiveram graves problemas financeiros (MEYER-OHLE, 2002).

\subsection{Relação entre GC e Operações de Fusões e Aquisições (F\&A's) e Privatizações}

Normalmente, o nível de concentração na entidade resultante após uma fusão é menor, pois há maior número de acionistas fora do grupo de controle. Esse menor nível pode trazer influências importantes para a GC e a gestão estratégica, pois os grandes acionistas podem ter reduzida sua capacidade de controle no negócio - aumentando, por conseguinte, o poder dos gestores (SHEN; GENTRY, 2014).

Objetivos governamentais em um processo de privatização podem influir na estrutura de GC e de controle em empresas privatizadas. Se o governo buscar vender pelo maior preço possível, um leilão público pode ser o melhor caminho - passando a entidade ao controle de grandes investidores, com suficiente interesse e poder para controlar o pessoal gerencial. Se o objetivo for permitir a possibilidade de controle por amplos grupos da sociedade, a venda pode ser diretamente ao público a preços abaixo do esperado de modo a permitir que os compradores obtenham rápidos ganhos de capital. Já as empresas familiares ou de capital fechado não são controladas nem por governos nem pelo mercado acionário. Normalmente, ainda estão em mãos das famílias fundadoras. Embora haja situações com gestores profissionais, os proprietários controlam as principais decisões. Uma das decisões mais importantes dessas 
companhias é a eventual abertura de seu capital em Bolsa, o que traz benefícios, como acesso mais facilitado a recursos do mercado financeiro (SHEN; GENTRY, 2014).

\subsection{Situações de GC em uma Organização do Terceiro Setor}

O Grupo Luta Pela Vida (GLPV) foi criado, em 1995, por médicos, professores, empresários e voluntários, gerindo o Hospital do Câncer de Uberlândia. É uma entidade filantrópica sem fins lucrativos. O GLPV foi reconhecido como de Utilidade Pública Municipal; Utilidade Pública Estadual e Federal e reconhecido pelo Conselho Nacional de Assistência Social (CNAS). O Hospital do Câncer, em Uberlândia, foi construído em área cedida pela Universidade Federal de Uberlândia. Oferece ambulatório de quimioterapia, radioterapia e internações pelo sistema day clinic. O número médio de atendimentos é de 5.500 pacientes/mês. O telemarketing é a principal fonte de receitas, captando em média R\$ 148 mil/mês. Outras fontes: empresa participativa; núcleo de voluntários; contribuintes; eventos; loja. Tais recursos são canalizados para a manutenção e construção de novas obras do hospital; sendo objeto de análise pelo Conselho Fiscal; Auditoria; Receita Federal; e CNAS (LEAL; FAMÁ, 2007).

O GLPV mantém a auditoria anual nas suas Demonstrações Financeiras, e ainda usa uma consultoria externa para avaliar suas normas e procedimentos internos. Seu Conselho Deliberativo (CD) delineia as metas da entidade dos fins previstos no Estatuto. O CD também tem a função de aprovar o orçamento e as contas da entidade. Publica-se trimestralmente um informativo aos doadores, voluntários e pacientes do Hospital do Câncer, para comunicar as ações e os eventos ocorridos. A gestão foi profissionalizada desde 2003 mediante a contratação de um administrador, a quem se atribui o planejamento e controle interno das ações administrativo-financeiras da entidade (LEAL; FAMÁ, 2007).

\section{Metodologia}

Um estudo de caso, segundo Yin (2005), apresenta a finalidade de analisar em profundidade o fenômeno em questão ou, ainda, descrever e explicar determinada situação e o contexto na vida real 
em que ela ocorre. Tal estratégia de pesquisa é adotada: a) quando não há maneira de se controlar os fatos; e b) quando o estudo trata de fenômenos da atualidade que estão inseridos em situações reais.

Nas ciências sociais, o estudo de caso passou a ser considerado como uma forma de estudar e analisar de modo exploratório ou descritivo, entre outras coisas, alguma organização ou um grupo de pessoas. Um estudo de caso pode envolver uma ou mais unidades de análise, tratando-se de casos múltiplos na segunda situação. A última se verifica quando o pesquisador pretende descrever mais de uma organização ou evento, bem como quando o objetivo primordial seja o de se fazer comparações. Há fenômenos que apresentam uma elevada complexidade em sua mensuração. Nestes, o estudo de caso se mostra como uma ferramenta eventualmente viável (SENGER; PAÇO-CUNHA; SENGER, 2004).

Em um estudo de caso os seguintes elementos de um projeto de pesquisa são importantes (YIN, 2005): a) questões de pesquisa do tipo "como e por quê?"; b) objetivos, em estudos exploratórios; c) unidades de análise escolhidas, que são ligadas à maneira pela qual as questões iniciais de pesquisa foram definidas; d) o nexo que correlaciona os dados à finalidade do estudo; e e) critérios adotados para a interpretação dos resultados.

No presente estudo de caso sobre falhas na aplicação dos princípios de GC, esses elementos são: a) descrição dos problemas nas companhias estudadas e análise dos mesmos, de modo a verificar os princípios que não foram seguidos; b) o objetivo principal do estudo é destacar a importância da prática dos princípios da GC, justamente em situações onde os mesmos não estiveram presentes; c) as organizações escolhidas foram as que diversos trabalhos acadêmicos tratam; houve uma intensa busca, em: Teses USP; Portal da CAPES e Google Acadêmico; d) o nexo entre o objetivo e as unidades de análise reside no fato de terem sido escolhidas companhias com problemas notórios, e às quais os próprios autores afirmam ter havido problemas de GC; e e) os critérios para a interpretação dos resultados constituem os próprios princípios da boa GC.

Yin (2005) também afirma que o problema de viés em ciências sociais pode também ocorrer em experimentos que envolvam outros 
métodos, como questionários e pesquisas quantitativas.

O presente estudo se constitui como descritivo, exibindo diversas situações de falhas de GC, difíceis de serem mensuradas da forma quantitativa. A riqueza do estudo se deve ao fato da atratividade e atualidade de tais casos.

\section{ANÁlise de SituAções PROBlemáticas DE GC}

\subsection{Em Instituições Financeiras}

\subsubsection{Bernard Madoff}

Madoff conduziu uma fraude por cerca de duas décadas, gerando perdas estimadas em US\$ 64 bilhões, incluindo os retornos que não foram feitos às aplicações. Resgates de US\$ 7 bilhões na crise de 2008 levaram à confissão de Madoff aos seus filhos em 10/12/2008 de que sua firma era uma fraude. No dia seguinte, seus filhos o entregaram ao FBI e foi preso. Tudo começou, segundo seu depoimento, quando teve perdas no início dos anos 1990, e não quis admiti-las, preferindo gerar falsos retornos. Ao começar tal prática, não conseguiu parar mais. Causas para seu esquema durar tanto: a) detinha uma forte reputação; b) os fiscais da SEC nunca analisaram com profundidade suas contas; c) os retornos prometidos eram altos, mas não irreais; d) Madoff circulava entre celebridades; e) Madoff não aceitava facilmente as aplicações em seus fundos; f) durante anos, os resgates foram honrados; e g) havia diversos fundos e bancos que traziam recursos a Madoff (LEWIS, 2012).

\section{Análise:}

Os quatro princípios da GC foram descumpridos por Madoff, causando prejuízos bilionários.

\subsubsection{Outras Situações}

Nos anos 1970, o Chase Manhattan ressentiu-se do estilo de gestão de David Rockefeller, preocupado com diplomacia mundial e negligenciando os clientes e os problemas de suas comunidades (KLEIN, 2001). Outros problemas (ROCKEFELLER. 2003): a) um colapso no sistema de gerenciamento de operações, com declínio nos lucros e aumento nas queixas dos consumidores; em 1972, o 
próprio Rockefeller fora alertado por ninguém menos que Frank Cary, presidente da IBM, dos problemas em seus sistemas, porém, durante dois anos, não enfrentou a questão; b) o Chase emprestou US\$ 97 milhões ao varejista W. T. Grant, que faliu; c) os lucros caíram de US\$ 182 milhões, em 1974, para US\$ 105 milhões em 1975; d) perda de espaço ante o crescimento internacional do Citybank. Desde os anos 1960, Rockefeller tentara internacionalizar o Chase, porém, a existência de dois presidentes nessa época atrapalhou a sua efetiva implantação; e e) a falência da Chase Manhattan Mortgage and Realty Trust (CMART). Rockefeller reconhece que concordar com a criação dessa empresa, permitir que fosse vítima de políticas de empréstimos agressivas, e utilizar o nome do Chase foram as piores decisões que tomou como presidente. Entre 1971 e 1974, o Chase e suas subsidiárias aumentaram o financiamento imobiliário de US\$ 2 para US\$ 5 bilhões. O CMART faliu, ao custo de US\$ 1 bilhão ao Chase.

O Banco Nacional tinha problema de liquidez em função de créditos incobráveis, denominados internamente "Contas de Natureza 917". Tais operações se iniciaram em 1986, época em que o Banco efetuou uma série de empréstimos a empresas de pequeno porte. Centenas dessas empresas vieram a enfrentar dificuldades financeiras, encerrando suas atividades sem liquidarem seus compromissos. Ao invés de se lançarem tais valores como créditos em liquidação e, depois, baixados em prejuízo, tais "empréstimos" foram mantidos, com as datas de vencimento "prorrogadas". Com o tempo, tais negócios já eram o maior ativo do banco. Apesar desse quadro, foram pagos dividendos em todos os anos de 1988 a 1995. O banco estava com passivo a descoberto desde 1990 e com patrimônio líquido em mais de 20 bilhões de reais no fim de 1995. A "criação" de lucros permitiu a distribuição de dividendos e a venda das ações pelos administradores, que esconderam a situação de insolvência, encaminhando falsas demonstrações ao Banco Central de 1986 até sua quebra em 1995, devido a créditos de duvidosa qualidade no valor de US\$ 5 bilhões (VANASCO, 1998; CUPERTINO, 2006).

Em 1991, a Salomon Brothers, mediante um de seus corretores, se envolveu na aquisição de títulos do Tesouro dos EUA acima da participação permitida pelas autoridades - inclusive utilizando 
fundos de clientes. O superior imediato defendeu o corretor, em uma reunião de cúpula, esse superior e outros dois executivos concordaram em informar ao Governo em um prazo de quatro meses, porém, nada foi feito. $\mathrm{O}$ corretor e os três executivos foram demitidos (THOMS, 2008).

Em 1997, um antigo trader do Chemical Banking foi condenado a três anos de prisão por ter causado prejuízos à sua organização em função de apostas em moedas. O trader declarou-se culpado por conspiração e falsificação de documentos contábeis (VANASCO, 1998).

Desde o início, as operações de Nick Leeson na filial de Cingapura do Barings não eram protegidas pelas respectivas e necessárias atividades de hedge, sendo, portanto, posições em aberto. Talvez tenha atuado assim para proteger seus bônus, que foram de $£ 130$ mil em 1993, tendo proposto nada menos que $£ 450$ mil para 1994. Leeson apenas poderia atuar em nome de clientes corporativos, mas já a partir de 1992 começou a operar em nome do próprio Barings. Leeson poderia apenas manter posições a serem fechadas ao final do dia, mas, superou amplamente tais limites, com milhares de contratos; esteve sujeito a riscos inerentes à atividades, ampliados pelo fato de não fazer hedge de suas atividades. Leeson também forjou inúmeras operações de hedge para esconder o que fazia ilegalmente. Os contínuos pedidos de recursos de Leeson chegaram a cerca de astronômicos $£ 400$ milhões apenas nas três semanas antes do colapso, ou seja, não havia qualquer supervisão de suas atividades e nenhuma ideia do que estava acontecendo naquela subsidiária. O pior de tudo: em todas suas "apostas", o mercado foi na direção oposta; mais grave ainda: os derivativos autorizados a ele eram básicos, de fácil compreensão e implementação. Também parecem escandalosas as falhas dos diversos níveis de hierarquia em monitorar o que Leeson fazia, bem como as falhas dos auditores externos e internos. Parece oportuno que organizações que operam com derivativos tenham mecanismo de controle. Também cabe pensar em sistemas informatizados para que as Bolsas de Valores possam monitorar as atividades dos traders em geral, identificar elevados prejuízos ou posições em aberto (STONHAM, 1996).

Em 1984, o Daiwa Bank permitiu que seu escritório de New York operasse com títulos do Tesouro dos EUA, com limites de 
US\$ 3 milhões, sob a supervisão de Toshihide Iguchi. O escândalo do Daiwa Bank foi finalmente reportado por Iguchi em 18/07/1995 em uma carta de 33 páginas. Porém, o presidente da organização não divulgou logo as perdas, planejando fazê-lo em dois meses; tal atitude exigiu forjar diversos documentos. O problema é que desde 1992 o Federal Reserve Bank of New York estava preocupado com as operações do Daiwa. Com a publicação das perdas nos EUA, em menos de dois meses o Daiwa foi indiciado e condenado a pagar multas de US\$ 340 milhões - as maiores de qualquer banco nos EUA até a data. Iguchi foi condenado a dois anos de prisão e a pagar US\$ 2 milhões. Finalmente, o Daiwa foi obrigado a encerrar suas operações nos EUA (MONROE-SHERIDAN, 2015).

O SocGen foi criado em 1864, tornando-se o maior da França nos anos 1920. A Europa aboliu a separação de atividades bancárias de varejo, seguros e títulos (a ser apenas seguida em 1999 pelos EUA) criando oportunidades aproveitadas para o crescimento do SocGen. Em 1987, o SocGen foi privatizado, após 42 anos de controle estatal. De 1997 a 2004, o SocGen fez diversas aquisições internacionais, chegando em meados de 2010 à $4^{\underline{a}}$. posição entre os bancos europeus no quesito de ativos geridos. Em 2004, foi criado o SG Global Securities Services for Investors, para fornecer serviços globais ligados a títulos e derivativos. Jérôme Kerviel atuava como trader encarregado de fazer hedge das operações: se fosse comprada uma ação na expectativa de um crescimento, ele deveria vender tais ações no mercado futuro. Em 2005, Kerviel já começou a atuar em transações fora de seus limites. Suas apostas o levaram a ganhos a descoberto de $€ 500$ milhões até meados de 2007; com medo de reportá-los, fez operações de hedge no sentido contrário para simular que estava apenas cumprindo seu dever. O mercado começou a mudar de direção, mas, seu sucesso inicial o tornou presunçoso, com posições de nada menos que $€ 50$ bilhões até o início de 2008, o que causou perdas de $€ 4$,9 bilhões ao SocGen. Em fevereiro de 2008, o SocGen finalmente descobriu a extensão das atividades de Kerviel e decidiu liquidá-las, apesar do momento ruim do mercado, informando apenas as autoridades financeiras francesas e não ao Governo - para evitar danos à imagem do banco. Ao implementar tal medida, incorreu nessas perdas, mas pôde salvar sua reputação. Além do SocGen ter sobrevivido por ter porte 
para enfrentar suas perdas, vários concorrentes tiveram prejuízos em função da crise do mercado de hipotecas nos EUA. A independência do SocGen também contou com três fatores: a) a possibilidade de o banco vir a ser adquirido por rivais estrangeiros enfrentaria o nacionalismo francês; b) se rivais franceses comprassem o SocGen teriam formado um grupo imenso - com grande chance de não autorização por parte da autoridade europeia encarregada da concorrência; e c) o SocGen emitiu ações, em 2008, para aumentar seu capital e manter sua independência. Kerviel foi condenado a pagar multas de $£ 375$ mil e a cinco anos de prisão - porém, sendo solto após cinco semanas, mesmo tendo sido responsável pela maior fraude bancária até a época, bastando que não voltasse a atuar em mercados financeiros; de fato, passou a atuar em uma empresa de informática, na área de segurança e desenvolvimento de sistemas (CANAC; DYKMAN, 2011).

\section{Análises:}

Chase Manhattan: o estilo de gestão de Rockefeller "focado em diplomacia" feriu os interesses dos minoritários (fairness).

Banco Nacional: os quatro princípios foram descumpridos, com o falseamento de relatórios financeiros, que levaram ao pagamento de dividendos sobre lucros fictícios aos acionistas, além de honorários aos executivos - ferindo os direitos dos minoritários e demais stakeholders.

Salomon Brothers: os quatro princípios foram descumpridos.

Chemical Bank: embora apenas um colaborador da firma tenha tido um comportamento inadequado, os quatro princípios foram descumpridos. Ou seja, sob os aspectos práticos, um trader negocia em nome da sua organização, com recursos dela própria ou até mesmo dos clientes.

No Barings, no Daiwa Bank e no SocGen os quatro princípios foram descumpridos.

Nicholas Leeson causou a quebra do Barings, enquanto que Jerome Kerviel - um simples trader da matriz francesa do Société Générale (SocGen) - causou prejuízos de $€ 4,9$ bilhões à sua organização em 2008. Nenhum deles era oriundo de universidades de prestígio nem membro de grupos da elite social. Tanto Leeson quanto Kerviel atuaram fora de seus limites por um considerável 
tempo. Nos dois bancos, não havia separação entre as atividades de back office e as demais; de fato, Leeson atuara na Indonésia no back office do Barings, e em Cingapura estava encarregado dessa posição apesar de ser também um trader; de fato, um relatório de 1994 advertira ao Barings dos riscos de Leeson atuar em Cingapura nessas duas posições, mas foi ignorado. Kerviel escondeu fraudulentamente suas operações fora de seus limites, jogando-as ficticiamente para o ano seguinte, de modo a não atrair a atenção do gestor de risco; sua experiência em back office o fez conhecedor dos sistemas de informática que permitiram a ele fazer as operações fictícias de hedge e esconder suas atividades escusas (CANAC; DYKMAN, 2011). Segundo Baxter Jr. (1997), as quebras de Daiwa e Barings representam eventos importantes, pois envolvem cifras bilionárias e as autoridades governamentais não anteviram qualquer problema. Nessas situações, Toshihide Iguchi e Nicholas Leeson detinham poderes que feriam os princípios da GC (BAXTER, 1997): A) no Daiwa, Iguchi atuava tanto como trader e no back office - uma prática que fere os princípios mais elementares da GC. Assim, Iguchi vendeu títulos de clientes para financiar compras do próprio portfólio do banco - uma prática intolerável. Teve prejuízos de US\$ 50 mil em 1983, mas, ao invés de informá-las à matriz, o que poderia afetar seus bônus, preferiu escondê-las e tentar cobri-las. Até 1995, tais perdas já haviam chegado a US\$ 1,1 bilhão em 30 mil transações não autorizadas. B) Leeson, do Barings, comandava tanto as operações de back office e de trader em Cingapura, chefiando toda a equipe, tendo, portanto, poderes de realizar negócios acima dos limites da filial. Estava com 25 anos de idade. Em 1992, um contrato de futuros gerou perdas de $£ 20$ mil, ano em que Leeson era recém-chegado à filial. Com medo de perder seu bônus, Leeson não reportou isso a Londres.

\subsection{Em Organizações Industriais e de Serviços}

Em 1998, a canadense YBF Magnex International, produtora de bicicletas e outros itens, teve $95 \%$ de perdas do valor de suas ações, devido a acusações de envolvimento com a máfia russa. Em função disso, investidores institucionais com mais de 50\% do capital da firma, representados no Conselho de Administração, trocaram a 


\section{Diretoria (CHEFFINS, 2014).}

A Enron foi criada, em 1985, pela fusão de duas empresas. Todo seu processo decisório era focado em grandes decisões, e na fuga dos problemas, em função da arrogância dos dirigentes. Além disso, a interpretação dos aspectos legais era bastante ampla. Houve conflito de interesses com os auditores independentes, que também prestavam consultoria à Enron. Foram erigidas cerca de 900 sociedades de propósitos específicos (SPE's) em paraísos fiscais, sem o conhecimento do Conselho de Administração, canalizando lucros da firma aos executivos. As principais falhas vieram a público, e a falência se deu em 2001 (JUNIOR, 2005; THOMS, 2008).

A Satyam Computer Services foi criada em 1987; seu chairman, Ramalinga Raju falseou os lucros e as receitas de todos os trimestres de 2003 a 2008. Houve a criação de receitas e de contas falsas; uma rede de 356 empresas foram usadas para desviar recursos da Satyam; parece que parte dos recursos foi usada na compra de imóveis. Foi o maior escândalo empresarial da Índia até a época. A empresa atuava em 66 países com 52.865 trabalhadores e 690 clientes - incluindo 185 da lista das 500 maiores da Fortune. O próprio chairman trouxe os problemas a público, em seu dizer, procurando salvar a companhia, mas era tarde. Em dezembro de 2008, o Banco Mundial desnudou problemas da empresa, dizendo-a inelegível para atender certo contrato; logo antes, a empresa tentara adquirir duas companhias de filhos do chairman - gerando protestos na Bolsa de New York. Assim, em 25/12/2008, veio o pedido de desculpas e a renúncia do chairman em janeiro/2009. A companhia foi comprada pela Mahindra Tech. Vários executivos da Satyam, inclusive Raju, foram acusados de inúmeros crimes (BHASIN, 2016).

A Justiça dos EUA fez Charles Wang devolver quase 50\% dos US\$ 670 milhões em honorários que recebeu da empresa que presidia, a Computer Associates, relativos apenas a 1999; tal valor fora a maior compensação de um presidente já reportada nos EUA até então (HITT; IRELAND; HOSKISSON, 2001, p. 423-424 e 508).

Al Dunlap, que havia sido presidente de diversas empresas, nas quais fizera um trabalho de reestruturação, foi contratado na Sunbeam Corp. Mesmo usando seus tradicionais hábitos de venda de ativos e de demissões, os resultados não vieram. Assim, tentou 
vender a organização, novamente sem sucesso. Então, adquiriu outras três empresas para forjar um fortalecimento da Sunbeam e sua posterior venda. Porém, as dívidas cresceram, e veio um prejuízo no primeiro trimestre/1998. Um estudo contábil mais elaborado revelou que os lucros de 1997 eram falsos; com a correta apresentação dos resultados de 1997, ao invés de lucros vieram prejuízos de US\$ 6,4 milhões e o Conselho de Administração demitiu Dunlap (HITT; IRELAND; HOSKISSON, 2001, p. 510).

Fran Tarkenton, da KnowledgeWare, inflou os números de receitas da empresa, com falsas receitas de US\$ 8 milhões mediante ligações telefônicas, para vender a empresa com um preço superestimado. Segundo o esquema criado, havia receitas mesmo sem a confirmação do potencial cliente. Tarkenton pagou US\$100 mil à SEC em multas, além de US\$ 54.187 dos bônus que recebera. O mesmo ocorreu com a Cendant Corp, durante três anos antes de a empresa ser vendida. Suas receitas tiveram que sofrer baixas de US\$ 511 milhões - o que fez as ações caírem de US\$ 41 a menos de US\$ 10, representando uma perda de US\$ 29 bilhões em valor (HITT; IRELAND; HOSKISSON, 2001, p. 510).

A WorldCom teve um rápido crescimento mediante F\&A's. Cerca de 50 de seus 50 mil funcionários participaram de um enorme conjunto de fraudes, que levaram a empresa a falir em 2002, a maior quebra dos EUA. O Presidente, Ebbers, foi sentenciado a 25 anos. Ao invés de lucros de US\$ 10 bilhões de 2000 a 2002, a empresa teve astronômicos prejuízos de US\$ 73 bilhões, por tais F\&A's (THOMS, 2008).

\section{Análises:}

YBF: falha de compliance.

Enron: os quatro princípios da GC foram descumpridos.

Satyam: os quatro princípios da GC foram descumpridos.

Computer Associates: a elevada remuneração paga ao Presidente da companhia feriu os interesses dos minoritários (fairness).

Gestão de Al Dunlap na Sunbeam: os quatro princípios da GC foram descumpridos.

KnowledgeWare e Cendant: os quatro princípios da GC foram descumpridos. 
WorldCom: os quatro princípios da GC foram descumpridos.

\section{Problemas de GC no Brasil: OGX}

Com um portfólio razoável, fatores de risco bem explicitados, profissionais experientes, e mesmo sem ter extraído uma gota de petróleo, a OGX abre seu capital em julho de 2008, tornando-se a maior das captações da bolsa brasileira, obtendo recursos no valor de R \$ 6,71 bilhões. A OGX, com cerca de um ano de vida foi avaliada pelo mercado em R $\$ 52$ bilhões. Em fatos relevantes, a empresa divulgou descobertas nos primeiros cinco poços, estimando que, em 2019, produziria 2,89 milhões de barris por dia (b/d). Mas, em 2010, vários executivos deixam a empresa, devido a conflitos com seu criador, Eike Batista. Em maio de 2011, a consultoria DeGolyer \& MacNaughton publica relatório afirmando que a companhia detinha reservas provadas de apenas 102 milhões de barris. Em julho de 2011, o início da produção da OGX em seu primeiro campo, Tubarão Azul, foi de $5 \mathrm{mil} \mathrm{b/d} \mathrm{-} \mathrm{três} \mathrm{vezes} \mathrm{menos} \mathrm{do} \mathrm{que} \mathrm{o} \mathrm{espe-}$ rado. Após isso, o Banco Merrill Lynch sugeriu uma redução do preço das ações da OGX de $\mathrm{R} \$ 19,50$ para $\mathrm{R}$ \$ 7,30. Mas, a queda foi a $\mathrm{R} \$$ 6,00/ação, com a demissão do Presidente e dificuldades de obtenção de crédito. Em 01/07/2013, a empresa comunicou à CVM que abandonaria a produção em seu campo Tubarão Azul e seus outros três campos, fazendo o preço de suas ações caírem a $R$ \$ 0,19 no início de outubro/2013; nessa ocasião, a empresa afirmou que não pagaria os juros de sua dívida externa, avaliada em US\$ 3,6 bilhões. Em 30/10/2013, a OGX faz um pedido de Recuperação Judicial, passando 95\% das ações aos credores; nesse ano, a OGX lançou $\mathrm{R} \$ 11,3$ bilhões na conta de prejuízos (SILVA, 1994, p. 174).

\section{Análise:}

As informações levadas a público em torno do volume esperado de produção - e, por conseguinte, de suas reservas- parece que foram grandemente exageradas pela OGX. A saída de vários de seus executivos, em 2010, parece corroborar tal afirmação. Desse fato, se pode afirmar que os quatro princípios da GC não foram cumpridos.

\section{ConClusões}

A importância das boas práticas de GC foi exibida do ponto de 
vista positivo sob seus aspectos teóricos, mediante diversos autores. A apresentação de Estudos de Casos Múltiplos, de vários setores da economia, em que se apontam falhas em sua consecução, ilustram os riscos desse descumprimento aos acionistas - em especial, os minoritários - e a todos os demais stakeholders. Falências de grupos de grande porte como a Enron significam perdas imensas de empregos, recursos públicos na forma de impostos não recolhidos, perdas a todos os fornecedores e à comunidade financeira que havia realizado empréstimos à firma.

Madoff representa uma situação limite de falha de GC, pelo fato de lidar com recursos de inúmeras pessoas e fundos e por ter atuado de modo fraudulento por um tempo considerável; o conjunto de razões apontado para ter podido atuar por tanto tempo merece consideração. Por sua vez, Charles Wang poderia ser visto nesse conjunto como uma situação de menor gravidade, não tanto pelos recursos envolvidos - aliás, devolvidos a mando das autoridades mas, por representar uma situação pontual.

Rockefeller teve as situações de sua gestão que foram apontadas, nas quais os resultados ao banco por ele comandado não foram felizes. Prejuízos podem ocorrer como risco natural de qualquer negócio, mas o estilo de dirigir um banco preocupado com "diplomacia geral" não se parece coadunar com os objetivos gerais do negócio.

As situações de: Salomon Brothers e Chemical Bank são muito semelhantes, havendo descumprimento de regras básicas, que trouxeram problemas diversos. Mas, o Banco Nacional veio à situação de falência após um longo período de falsear suas demonstrações contábeis.

As falhas ocorridas no Barings, no Daiwa Bank e no SocGen estão melhor documentadas, e apresentam análises mais complexas por parte de textos acadêmicos. No primeiro caso, o banco encerrou as atividades, o Daiwa cessou sua atuação nos EUA e o último conseguiu sobreviver. Todos eles representam situações de falhas graves e continuadas de GC.

A Enron é citada em inúmeros estudos como das piores falhas em GC, inclusive, com a WorldCom, tendo sido uma das motivadoras de novas leis, como a Sorbonnes-Oxley.

A YBF, a Satyam, a KnowledgeWare, a Cendant e a gestão de Al 
Dunlap na Sunbean são muito semelhantes, havendo descumprimentos legais, e os consequentes descuidos em relação aos direitos dos acionistas minoritários. Dessas situações, se destaca a Satyam, pelo fato de ser a maior falha de GC jamais ocorrida na Índia até a época.

A OGX em nosso país apresenta uma situação em que foram obtidos recursos do público mediante afirmações de reservas de petróleo e de expectativas de produção futura aparentemente irreais.

A respeito de estudos correlatos, Minadeo (2018) apresenta Estudos de Casos Múltiplos de empresas com falhas em suas práticas de GC analisados à luz de L'Huillier (2014) e Martin, Santos, Dias Filho (2004). Estudos futuros podem abordar situações problemáticas de GC mediante fontes primárias, visando a elaboração de Estudos de Casos.

\section{REFERÊNCIAS}

ANDRADE, L. P. Governança Corporativa dos Bancos no Brasil. Dissertação (Mestrado em Administração). Rio de Janeiro: PUC-Rio, 2005.

ARNOLD, P. J. Global financial crisis: The challenge to accounting research. Accounting, Organizations and Society, 34 (2009), p. 803-809.

BAXTER JR., T. C. Breaking the Billion Dollar Barrier - Learning the Lessons of BNL, Daiwa, Barings and BCCI. Journal of Money Laundering Control, v. 1. Issue 1, p. 15-25, 1997.

BENITES, L. L. L.; POLO, E. F. A sustentabilidade como ferramenta estratégica empresarial: Governança Corporativa e aplicação do Triple Bottom Line na Masisa. Rev. Adm. UFSM, Santa Maria, v. 6, Edição Especial, p. 195-210, mai. 2013.

BERTUCCI, J. L. O.; BERNARDES, P.; BRANDÃO, M. M. Políticas e práticas de governança corporativa em empresas brasileiras de capital aberto. R. Adm., São Paulo, v. 41, n. 2, p. 183-196, abr./mai./jun. 2006

BHASIN, M. L. Creative Accounting Practices at Satyam Computers Limited: A Case Study of India's Enron. International Journal of Business and Social Research, v. 6. Issue 6, 2016. BORTOLON, P. M.; NETO, A. S.; SANTOS, T. B. Custos de Auditoria e Governança Corporativa. R. Cont. Fin. - USP, São Paulo, v. 24, n. 61, p. 27-36, jan./abr. 2013.

CALDAS, C. B.; TAMBOSI FILHO, E.; VIEIRA, A. M. Governança Corporativa e Sustentabilidade: uma relação necessária. Revista UNIABEU, v. 7, p. 353-369, 2014.

CANAC, P.; DYKMAN, C. The tale of two banks: Société Générale and Barings. Journal of the International Academy for Case Studies, v. 17, n. 7, 2011, p. 11-32.

CANNON, R.; HUGHEY, T.; FREDERIKSEN, M.; SMITH, M. Ethical erosion: how far from 
center are you? you may be further than you think: create an ethical culture by utilizing the five disciplines of an ethical culture. Journal of Health Care Compliance. 17.5 (September -October 2015).

CARVALHAL, R. L.; BORDEAUX-RÊGO, R. UFF: Relatórios de pesquisa em engenharia de produção, v. 10, n. 13, S/d. Teoria do Agente, Teoria da Firma e os Mecanismos de Governança Corporativa no Brasil.

CERDA, A. C. Tender Offers, Takeovers and Corporate Governance. São Paulo: The Latin America Corporate Governance Roundtable, 2000.

CHEFFINS, B. R. Hedge Fund Activism Canadian Style. University of British Columbia Law Review, jan. 2014, v. 47: 1, p. 1-33.

CHIZEMA, A.; YOSHIKATSU, S. The 'Company with Committees': Change or Continuity in Japanese Corporate Governance? Journal of Management Studies, 49:1, jan. 2012.

CUPERTINO, C. M. Earnings Management: Estudo de caso do Banco Nacional. R. Cont. Fin. - USP, São Paulo, n. 41, p. 110-120, mai./ago. 2006.

DAVIS, G. F.; KIM, S. Financialization of the Economy. Annu. Rev. Sociol., 2015, v. 41, p. 203-221.

DEDONATTO, O.; BEUREN, I. M. Análise dos impactos p a contabilidade no processo de implantação da governança corporativa em uma empresa. RC\&C - Revista de Contabilidade e Controladoria, ISSN 1984-6266. UFPR, Curitiba, v. 2, n. 3, p. 23-38, set./dez. 2010.

FORTUNA, E. L. P. A Governança Corporativa no Sistema Bancário - Uma Visão Orientada aos Depositantes, Credores e à Sociedade. Tese (Doutorado em Administração). Rio de Janeiro: Instituto COPPEAD de Administração, 2007.

FRANKS, Julian; MAYER B., Colin. Bank control, takeovers and corporate governance in Germany. Journal of Banking \& Finance, 22 (1998), 1.385-1.403.

GORDON, J. N. Pathways to Corporate Convergence? Two Steps on the Road to Shareholder Capitalism in Germany: Deutsche Telekom and DaimlerChrysler. COLUMBIA J. OF EUROPEAN LAW, 219-241, jan. 31, 2000.

HITT, M. A.; IRELAND, R. D.; HOSKISSON, R. E. Strategic Management - Competitiveness and Globalization. Thomson Learning: 2001. Fourth Edition.

HÖPNER, Martin; JACKSON, Gregory. An Emerging Market for Corporate Control? The Mannesmann Takeover and German Corporate Governance. Max-Planck-Institut für Gesellschaftsforschung: Discussion Paper 01/4; ISSN 0944-2073, Sept./2001.

JUNG, J.-y. Post-crisis restructuring of the corporate governance of Korean companies. The international journal of business in society, v. 13. Issue 1, p. 3-17, 2013.

KLEIN, M. M. (Ed.) The Empire State - A History of New York. Ithaca/London: Cornell University Press, 2001.

LADEIRA, D. L. Teoria dos Stakeholders no contexto da Governança Corporativa: um estudo de caso. Dissertação (Mestrado em administração). Belo Horizonte: FUMEC, 2009. 
LANZANA, A. P. Relação entre disclosure e governança corporativa das empresas brasileiras. Dissertação (Administração). São Paulo: USP, 2004.

LEAL, E. A.; FAMÁ, R. Governança nas Organizações do Terceiro Setor: Um estudo de caso. USP: SEMEAD, 10, 2007. In: Anais Eletrônicos.

LEWIS, M. K. New dogs, old tricks. Why do Ponzi schemes succeed? Accounting Forum, 36 (2012), 294-309.

MEYER-OHLE, H. The crisis of Japanese retailing at the turn of the millennium: a crisis of corporate governance and finance. Int. Rev. of Retail, Distribution and Consumer Research, 12:1, jan. 2002, p. 13-28.

MINADEO, R. Corporate governance: concepts, situational analysis and reflections on the situations based on theoretical framework of L'Huillier (2014) and Martin, Santos, Dias Filho (2004). Brazilian Journal of Development, Curitiba, v. 4, n. 3, Edição Especial, p. 995-1019, june 2018. ISSN 2525-8761.

MONROE-SHERIDAN, A. R. Substance overload: a comparative examination of japanese corporate governance law through the lens of the Daiwa Bank case. Washington International Law Journal, v. 24, n. 2, april 2015, p. 319-362.

OLIE, R. Culture and Integration Problems in International Mergers and Acquisitions. European Management Journal, v. 8, n. 2, june 1990, p. 206-215.

PICHHADZE, A. Mergers, Acquisitions, and Controlling Shareholders: Canada and Germany Compared. Banking \& Finance Law Review, v. 18, p. 342-371, oct./2005.

PORTER, M. E. A Vantagem Competitiva das Nações. Rio de Janeiro: Campus, 1993. ROCKEFELLER, D. Memórias. Rio de Janeiro: Rocco, 2003.

SABBATINI, J. F. Comunicação organizacional e Governança Corporativa: uma interseç̧ão possível? Tese (Doutorado em Comunicação). São Paulo: USP, Escola de Comunicação e Artes, 2010.

SENGER, I.; PAÇO-CUNHA, E; SENGER, C. M. O Estudo de caso como estratégia metodológica de pesquisas científicas em administração: um roteiro para o estudo metodológico. CRA: Revista de Administração, v. 3, n. 4 (2004), p. 93-116, ISSN on-line 2317-6083.

SHEN, W.; GENTRY, R. J. A cyclical view of the relationship between corporate governance and strategic management. J. Manag. Gov. (2014) 18:959-973.

SIKKA, P. Financial crisis and the silence of the auditors. Accounting, Organizations and Society, 34 (2009), p. 868-873.

SILVA, E. F. Análise da queda de preço das ações da empresa OGX Petróleo e Gás Participações S/A desde sua abertura de capital até o ano de 2013. Monografia de Final de Curso (Ciências Econômicas). Curitiba, UFPR: 2014.

STONHAM, P. Whatever Happened at Barings? Part Two: Unauthorised Trading and the Failure of Controls. European Management Journal, v. 14, n. 3, p. 269-278, 1996.

THOMS, J. C. Ethical Integrity in Leadership and Organizational Moral Culture. Leadership, 2008, v. 4 (4), p. 419-442. 
TINOCO, J. E. P.; ESCUDER, S. A. L.; YOSHITAKE, M. O Conselho Fiscal e a Governança Corporativa: Transparência e Gestão de Conflitos. ISSN 1807-1821, UFSC, Florianópolis: Revista Contemporânea de Contabilidade, v. 8, n. 16, p. 175-202, jul./dez., 2011.

TRINDADE, L. Z.; NETO, S. B. Análise e percepção dos custos das práticas de governança corporativa: um estudo de caso. CONTEXTUS - Revista Contemporânea de Economia e Gestão - ISSNe 2178-9258, v. 12, n. 3, set./dez. 2014, p. 64-97.

VANASCO, R. R. Fraud auditing. Managerial Auditing Journal, v. 13. Issue 1, p. 4-71, 1998.

WAGNER III, J. A.; HOLLENBECK, J. R. Comportamento Organizacional. São Paulo, 2014, 3. edição.

WEISBACH. M. S. Corporate governance and hostile takeovers. Journal of Accounting and Economics, 16, p. 199-208, 1993.

WESTON, J. F. Finanças de Empresas (Campo e Metodologia). São Paulo: Atlas, 1969.

YIN, R. K. Estudo de Caso - Planejamento e Métodos. Porto Alegre: Bookman, Terceira Edição, 2005.

\section{ROBERTO MINADEO}

Analista em C\&T do CNPq, lotado na COENE - Coord. do Programa de Pesquisa em Energia.

Doutor em Ciências da Engenharia da Produção - COPPE/UFRJ

Mestre em Administração de Empresas - COPPEAD/UFRJ

Administrador - FEA/USP. E-mail: rminadeo@gmail.com .

Recebido em: 23-5-2017

Aprovado em: 10-10-2017

Avaliado pelo sistema double blind review.

Editor: Coordenação do PPGA/UMESP

Disponível em http://mjs.metodista.br/index.php/roc 